\title{
PENGEMBANGAN MODEL PANDUAN PEMBELAJARAN KETERAMPILAN PROSES SAINS BIOLOGI SMA/MA
}

\author{
Triana Asih \\ Pendidikan Biologi FKIP Universitas Muhammadiyah Metro \\ E-mail: asih.triana@yahoo.com
}

\begin{abstract}
Science learning in senior high school was designed with the goal of achieving the competencies of graduates that includes aspects of attitudes, skills, and knowledge competency. Skill aspect refers to the Scientific Approach. Skills such as observing the process are observing, trying, processing, serving, and reasoning. All of these skills, leading to the aspects that exist within SPS. Learning needs analysis conducted by researchers at the SMA/ MA class XI IPA that is in the Purbolinggo district of East Lampung SPS shows a lack of provision in the learning process. Supposedly, learning based on SPS is further enhanced, the researchers created a learning guide model based on SPS. The objectives of the reasearch: 1) produce a learning guide model based on SPS class XI, 2) improve outcomes (process) and output (learning cutcomes) biology learning class XI. Type of the research is Research and Development $(R \& D)$. The research was conducted in SMA N 1 Purbolinggo in class XI Science. Procedures R\&D is adapted from Borg and Gall consisting of five steps: 1) literature review and the results of relevant research, 2) Design and carry out preliminary study, 3) the development/conceptualization models, 4) test the model through experimentation, 5) revision of the model. conclusion; 1) learning guide SPS models has been validated by the user and learning experts, instrument validation, model validation, and it is suitable.
\end{abstract}

Kata Kunci: Model Panduan Pembelajaran, Keterampilan Proses Sains (KPS), Biologi Kelas XI

Keberhasilan suatu pendekatan yang digunakan dalam pembelajaran, salah satu kuncinya adalah keberhasilan guru dalam menyajikan materi pelajaran yang dapat memfasilitasi siswanya untuk mencapai kompetensi yang diharapkaan. Menurut kurikulum 2013, pembelajaran sains di SMA dirancang dengan tujuan pencapaian kompetensi lulusan dengan meningkatkan dan menyeimbangkan soft skills dan hard skills yang meliputi aspek kompetensi sikap, keterampilan dan pengetahuan. Aspek keterampilan yang dilakukan mengacu pada pendekatan sains (Scientific Approach) seperti keterampilan mengamati, menanya, mencoba, mengolah, menyaji, dan menalar, semua proses tersebut mengarah pada aspek-aspek yang ada dalam KPS. Namun, dalam studi awal Asih (2012) mengungkapkan bahwa guru-guru sekolah menengah belum memahami hakikat pengembangan KPS dan belum melakukannya.

Peneliti kemudian melakukan analisis kebutuhan pembelajaran pada sekolah-sekolah SMA/MA yang ada di kecamatan Purbolinggo Lampung Timur. Analisis kebutuhan yang dilakukan di sekolah negeri diwakili oleh SMA N 1 Purbolinggo, dan pada sekolah swasta diwakili oleh MA Muhammadiyah 1 Purbolinggo, dan didapati hasil analisis pada tabel 1 .

Berdasarkan data di atas, menunjukan bahwa kurangnya pemberian KPS pada proses pembelajaran. Salah satu penyebab masalah ini karena tidak adanya keyakinan dan pemahaman yang benar 
pada guru, bahwa hasil yang baik hanya bisa diperoleh dari proses yang baik juga. Ketidakserasian antara tuntutan kurikulum dan penilaian diduga menjadi penyebab utama kekurangbergariahan guru dalam mengembangkan KPS di Indonesia (Rustaman, 2005). Kondisi ini bisa menjadi kendala pada implementasi kurikulum 2013 yang sangat kental dengan pendekatan sains (Scientific Approach) yang mengarah pada aspekaspek KPS.

Model pembelajaran yang dibutuhkan adalah yang mampu menghasilkan kemampuan untuk belajar, bukan saja diperoleh sejumlah pengetahuan, keterampilan dan sikap saja, tetapi yang lebih penting adalah bagaimana pembelajaran keterampilan proses sains diharapkan dapat menjadi alternatif (Joice \& Weil, 1996). Model ini menekankan pada proses pencarian pengetahuan dari pada transfer proses pembelajaran, guru hanyalah seorang fasilitator yang membimbing dan mengkoordinasikan kegiatan belajar siswa. Fokus proses pembelajaran diarahkan pada pengembangan keterampilan siswa dalam memproses pengetahuan, menemukan dan mengembangkan sendiri fakta, konsep, dan nilai-nilai yang diperlukan. Siswa diberi kesempatan untuk langsung terlibat dalam aktivitas dan pengalaman ilmiah seperti apa yang dilakukan ilmuan. Di dalam model ini juga tercakup penemuan makna (meanings), organisasi, dan struktur dari idea tau gagasan, sehingga secara bertahap siswa belajar bagaimana mengorganisasikan dan melakukan penelitian. Model pembelajaran berbasis keterampilan proses sains berpotensi membangun kompetensi dasar hidup siswa melalui pengembangan keterampilan proses sains, sikap ilmiah, dan proses konstruksi pengetahuan secara bertahap.

Tabel 1: Analisis Kebutuhan Pelaksanaan pembelajaran berbasis KPS

\begin{tabular}{l|l|l|l}
\hline \multirow{2}{*}{ Nama Sekolah } & \multicolumn{3}{|c}{ Pelaksanaan pembelajaran berbasis KPS } \\
\cline { 2 - 4 } & Sering & $\begin{array}{l}\text { Jarang } \\
\text { kali })\end{array}$ & $\begin{array}{l}\text { Tdak } \\
\text { pernah }\end{array}$ \\
\hline SMA N 1 Purbolinggo & $16,44 \%$ & $48,11 \%$ & $35,45 \%$ \\
\hline $\begin{array}{l}\text { MA Muhammadiyah 1 } \\
\text { Purbolinggo }\end{array}$ & $13,33 \%$ & $36,67 \%$ & $50 \%$ \\
\hline
\end{tabular}

Tujuan penelitian dan pengembangan ini antara lain: 1) menghasilkan model panduan pembelajaran berbasis KPS biologi kelas XI, 2) meningkatkan outcome (proses) dan output (hasil belajar) pembelajaran biologi kelas XI. Produk hasil penelitian dan pengembangan ini menyajikan keterampilan proses dasar maupun terpadu yang dapat dilatihkan kepada peserta didik dengan uji coba baik eksperimen maupun non eksperimen, dan dapat di gunakan untuk membantu guru-guru SMA/MA menguasai keterampilan proses serta mengimplementasikan keterampilan proses dalam suatu kegiatan pembelajaran Biologi. 
METODE

Jenis penelitian ini adalah dan teknik analisis data dalam Research and Development (R\&D). Penelitian ini dilaksanakan di SMA N 1 Purbolinggo pada kelas XI IPA. Prosedur R\&D ini diadaptasi dari Borg and Gall yang terdiri dari lima langkah seperti pada gambar 1 .
Instrumen pengumpulan data penelitian ini menggunakan beberapa instrumen seperti analisis kebutuhan, validasi ahli, validasi model, observasi, dan tes yang terdapat pada Tabel 2 .

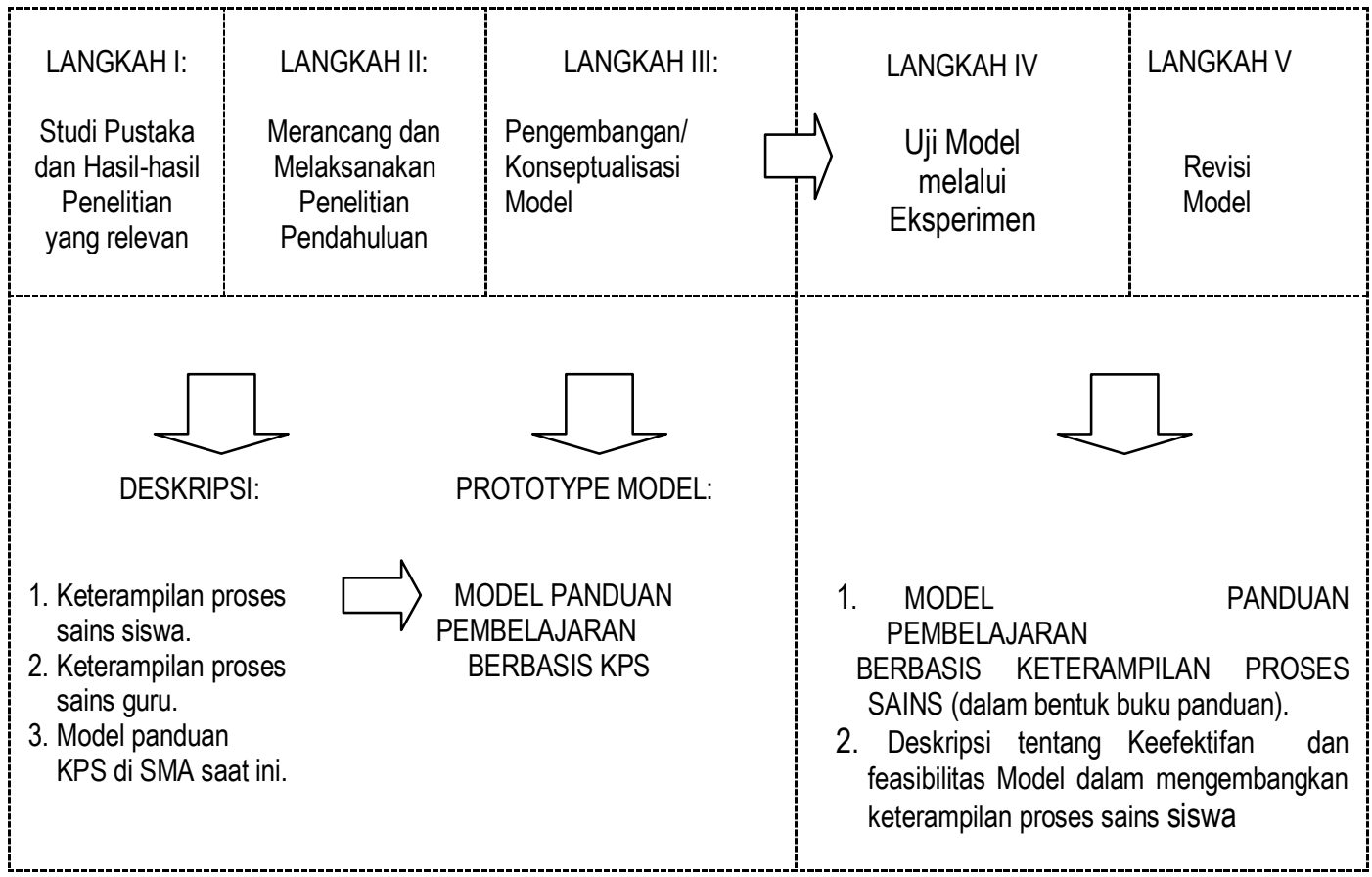

Gambar 1. Prosedur Penelitian dan Pengembangan KPS, Diadaptasi dari Brog \& Gall (1989:571)

Tabel 2. Instrumen Pengumpulan data dan Teknik Analisis Data

\begin{tabular}{|c|c|}
\hline $\begin{array}{c}\text { Instrumen } \\
\text { Pengumpulan } \\
\end{array}$ & Teknik Analisis Data \\
\hline $\begin{array}{l}\text { Analisis } \\
\text { Kebutuhan }\end{array}$ & Presentase KPS $=\frac{\text { Jumlah KPS yang terceklis }}{\text { Jumlah Siswa } \mathrm{x} \text { Jumlah Indikator }} \times 100 \%$ \\
\hline Validasi Ahli & Presentase Penskoran Ahli $=\frac{\text { Jumlah Skor yang diperoleh }}{5 \times 30} \times 100 \%$ \\
\hline $\begin{array}{l}\text { Validasi } \\
\text { Model }\end{array}$ & $\begin{array}{l}\text { Melalui Eksperimen Matching Pretest-Postest Control Group. Diuji } \\
\text { perbedaan secara statistik antara A dan B menggunakan Uji-t, data yang } \\
\text { dianalisis berupa data gain. } \\
\text { Normalisasi Gain }=\frac{\text { (Skor pos-tes }- \text { Skor pre-tes })}{\text { (Skor Maksimum }- \text { Skor pre-tes }}\end{array}$ \\
\hline Observasi & Skala Rating, diuji melalui Validitas dan Reliabilitas \\
\hline Tes & $\begin{array}{l}\text { Soal Pilihan Ganda, diuji (indeks kesukaran, daya beda, kekuatan option } \\
\text { validitas, reliabilitas) }\end{array}$ \\
\hline
\end{tabular}


Tabel 3. Hasil Penilaian Pengguna dan Ahli terhadap Model Panduan

\begin{tabular}{c|l|c}
\hline No. & \multicolumn{1}{|c|}{ Penilai } & Kategori \\
\hline 1 & Guru 1 : Nurhayati, S.Pd. & Sangat Baik (82\%) \\
\hline 2 & Guru 2 : Risma Diana, S.Pd. & Baik (76\%) \\
\hline 3 & Ahli : Dr. Hening Widowati, M.Si. & Sangat baik (97\%) \\
\hline
\end{tabular}

Ket.: *berdasarkan kategori tingkat kelayakan buku pelajaran menurut ahli dan pengguna

HASIL

Hasil produk pada penelitian dan pengembangan ini meliputi tiga pokok data hasil yaitu hasil identifikasi penilaian model panduan KPS oleh guru dan ahli pembelajaran, hasil analisis instrument KPS, dan hasil penerapan model.

1. Hasil Identifikasi Penilaian Model

Panduan KPS oleh Guru dan Ahli

Berdasarkan target pencapaian kelayakan untuk model panduan KPS, ketiganya telah memenuhi target pencapaian kelayakan untuk validasi ahli (expert) yaitu minimal baik.

Diperoleh tiga saran penting dari penilaian tersebut: (1) penilaian instrument KPS agar lebih dispesifikasikan ke dalam masingmasing macam-macam KPS; (2) materi uji coba langsung dicantumkan ke dalam model panduan pembelajaran KPS; (3) pembagian alokasi waktu pembelajaran pada RPP, harus benarbenar disesuaikan untuk pembagian beberapa jenis KPS yang di uji coba pada tiap pertemuan.

\section{Hasil Analisis Instrumen KPS}

Setelah melaksanakan uji coba instrumen, maka dilakukan analisis data berupa validasi dan reliabilitas dengan hasil analisis pada Gambar 2.

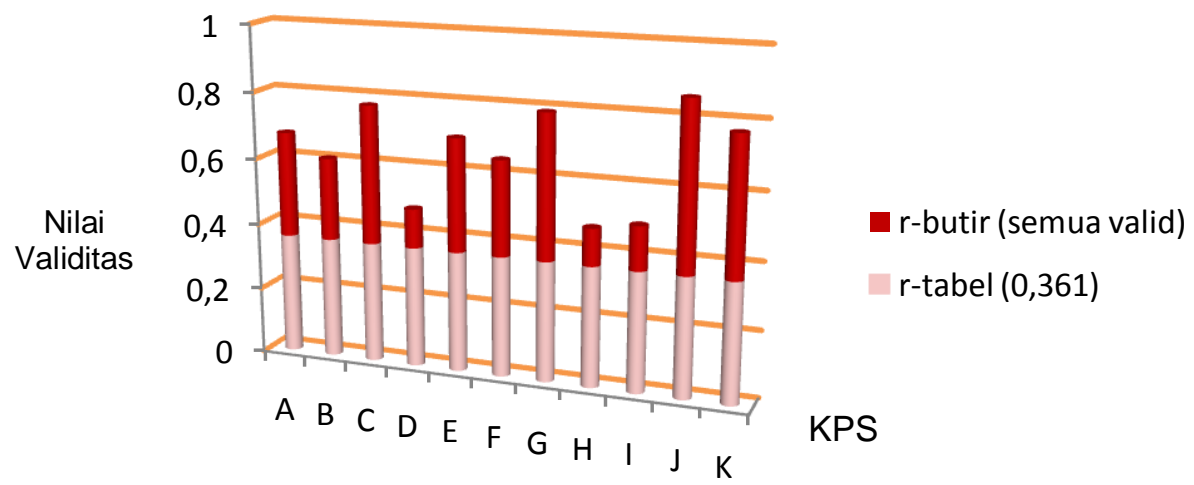

Gambar 2. Hasil Analisis Validitas melalui Korelasi $r$-Product momen

Ket:
A : Mengamati
B : Mengklasifkasikan
G : Menngidentifikasi variabel
C : Mengukur
D : Memprediksi
E : Hipotesis
F : Interpretasi Data
$\mathrm{H}$ : Mendefinisikan variabel secara operasional
I : Menyimpulkan
$\mathrm{J}$ : Mengkomunikasikan
$\mathrm{K}$ : Eksperimen 


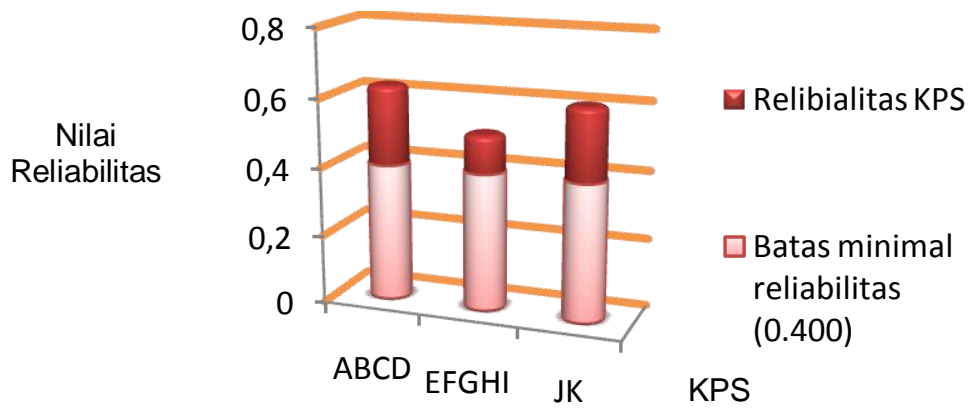

Gambar 3. Hasil Analisis Reliabilitas melalui Teknik Alfa Cronbach

Ket:
A : Mengamati
B : Mengklasifkasikan
C : Mengukur
D : Memprediksi
E : Hipotesis
F : Interpretasi Data

Berdasarkan Gambar 2 hasil analis dengan menggunakan rumus Korelasi Product Momen Pearson, diperoleh hasil $\mathbf{r}_{\text {hitung }}$ terkecil $=0,472$, $\mathrm{r}_{\text {hitung }}$ terbesar $=0,859$ dengan $r_{\text {tabel }}=$ 0,361 , berdasarkan data tersebut dapat dibandingkan bahwa $r_{\text {hitung }}>r_{\text {tabel }}$ berarti instrumen butir yang diuji semuanya dinyatakan valid. Analisis data selanjutnya berupa uji reliabilitas melalui teknik Alpha Cronbach. Hasil analisis melalui teknik Alpha Cronbach dapat dilihat pada Gambar 3.

Berdasarkan hasil perhitungan dengan rumus Alpha Cronbach diperoleh hasil sebesar $\mathrm{r}_{\mathrm{ABCD}}=(0,63)$, Berdasarkan kriteria reliabilitas bahwa nilai $(0,63), \quad$ termasuk kriteria reliabilitas tinggi.

Berdasarkan hasil perhitungan dengan rumus Alpha Cronbach diperoleh hasil sebesar $\mathrm{r}_{\mathrm{EFGHI}}=(0,51)$, Berdasarkan kriteria reliabilitas bahwa
G : Menngidentifikasi variabel

$\mathrm{H}$ : Mendefinisikan variabel secara operasional

I : Menyimpulkan

$\mathrm{J}$ : Mengkomunikasikan

$\mathrm{K}$ : Eksperimen

nilai (0,51), termasuk kriteria reliabilitas cukup.

Berdasarkan hasil perhitungan dengan rumus Alpha Cronbah diperoleh hasil sebesar $r_{\mathrm{JK}}=(0,61)$, Berdasarkan kriteria reliabelitas bahwa nilai $(0,61)$, termasuk kriteria reliabilitas tinggi.

\section{Hasil Uji Perbandingan Model Panduan KPS}

Hasil belajar yang dibandingkan merupakan skor perolehan (gain) siswa berdasarkan selisish dari pos-tes dan pre-tes yang telah dinormalisasi (gain normalize). Pengujian dilakukan pada kelompok subjek penelitian yang secara teoritis dikategorikan setara dan homogen.

Hasil analisis dan interpretasi data hasil pembelajaran menggunakan model panduan KPS pada pokok bahasan transport pada membran seperti terlihat pada Tabel 4 dan 5 . 
Tabel 4. Rata-rata Masing-masing Kelompok

\begin{tabular}{|c|c|c|c|c|c|}
\hline \multicolumn{6}{|c|}{ Group Statistics } \\
\hline & Kelas & $\mathrm{N}$ & Mean & Std. Deviation & Std. Error Mean \\
\hline Hasil & A & 30 & .7222 & .20781 & .03794 \\
\hline Test & B & 30 & .5716 & .33867 & .06183 \\
\hline
\end{tabular}

Tabel 5. Hasil Independent Sample T-test

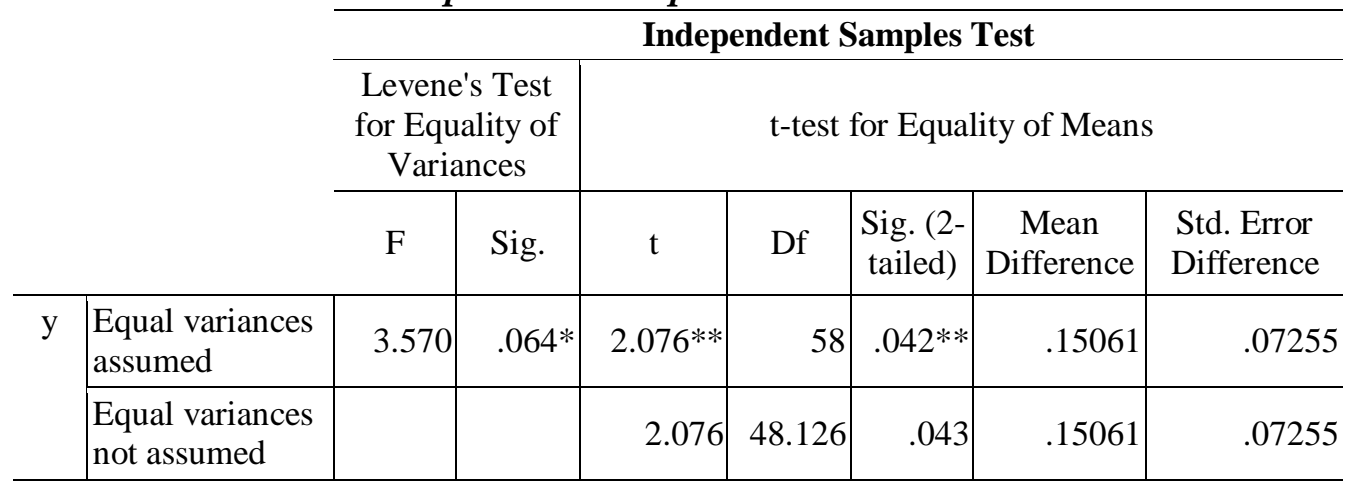

Ket $* *$ signifikan pada $\alpha=0,05$

Berdasarkan Tabel 4 terlihat jumlah data baik dari kelompok variabel perlakuan (treat) maupun dari kelompok variabel non perlakuan adalah sama, yaitu masing-masing 30 siswa. Rata-rata (mean) kelompok pelakuan adalah 0,72 (peningkatan tinggi) dan data kelompok non perlakuan 0,57 (peningkatan sedang). Data yang dianalisi merupakan data gain yang telah dinormalisasi ( $\mathrm{N}$-gain).

Berdasarkan analisis uji kesamaan dua rata-rata tabel 5 didapatkan nilai $\mathrm{t}$ hitung $>\mathrm{t}$ tabel $(2,076>1,70)$, maka Ho ditolak. Kesimpulan ada perbedaan rata-rata hasil belajar berbasis KPS dengan ratarata hasil belajar biologi tanpa proses pembelajaran berbasis KPS. Sedangkan analisis uji perbedaan dua rata-rata tabel 5 didapatkan nilai $\mathrm{t}$ hitung $>\mathrm{t}$ tabel $(2,076>1,70)$, maka Ho ditolak. Kesimpulan rata-rata hasil belajar biologi siswa melalui proses pembelajaran berbasis KPS lebih dari rata-rata hasil belajar biologi siswa melalui proses pembelajaran konvesional.

\section{PEMBAHASAN}

Berdasarkan hasil uji perbandiangan model panduan KPS, diketahui ada perbedaan rata-rata hasil belajar berbasis KPS dengan rata-rata hasil belajar biologi tanpa proses pembelajaran berbasis KPS. Hal tersebut dikarenakan, model panduan KPS menekankan bagaimana siswa belajar dan mengelolah perolehannya sehingga mudah dipahami dan digunakan dalam kehidupan di masyarakat. Dalam proses pembelajaran, siswa dapat memperoleh pengalaman dan pengetahuan sendiri, penyelidikan ilmiah melatih kemampuan intelektualnya (Subagio, Wiyanto, dan Marwoto : 2009). Hal tersebut didukung oleh penelitian Haryono (2006), Subagio (2009), Cholvistaria (2012) dan Yuniastuti 
(2013) bahwa, pembelajaran dengan menggunakan KPS berdampak pada kenaikan ketuntasan hasil belajar siswa.

Model panduan pembelajaran KPS ini juga dirancang dengan menekankan interaksi siswa terhadap lingkungannya, Melalui pengamatan siswa sendiri, siswa dapat menemukan jawaban atas permasalahan yang diperolehnya. Menurut Piaget (Karwono, 2012) menemukan bahwa perkembangan kognitif sebagian besar bergantung pada seberapa jauh anak akan aktif beinteraksi dengan lingkungannya. Di dalam kelas, siswa menemukan sendiri pengetahuan tersebut melalui interaksi inkuiri atau penemuan, karena pembelajaran biologi yang baik ialah pembelajaran yang dilandaskan pada prinsip keterampilan proses, dimana siswa menemukan dan mengembangkan sendiri fakta dan konsepnya. Hal tersebut didukung oleh penelitian Jehdoloh (2012), Asih (2012), dan Yuniastuti (2012) bahwa, melalui penemuan-penemuan yang dilakukan sendiri oleh siswa, maka KPS siswa dapat lebih ditingkatkan. Maka, untuk membekali guru-guru sebelum proses pembelajaran, model panduan pembelajaran KPS ini dapat menjadi alternatif untuk mengembangkan aspek psikomotorik pada pembelajaran biologi.

\section{KESIMPULAN DAN SARAN Kesimpulan}

1. Model panduan pembelajaran KPS yang dihasilkan telah divalidasi oleh pengguna dan ahli pembelajaran, validasi instrumen, validasi model, dan layak digunakan.

2. Uji coba produk melalui Independent t-test menunjukan bahwa; ada perbedaan rata-rata hasil belajar berbasis KPS dengan rata-rata hasil belajar biologi tanpa proses pembelajaran berbasis KPS. Hasil belajar biologi siswa melalui proses belajar menggunakan model panduan pembelajaran KPS lebih dari rata-rata hasil belajar biologi siswa melalui proses pembelajaran konvesional.

\section{Saran}

1. Guru agar dapat menggunakan model pembelajaran KPS, menguasai berbagai keterampilan proses, merancang skenario pembelajaran, dan dapat membuat LKS yang menyajikan pembelajaran menggunakan KPS.

2. Siswa agar lebih memahami macam-macam KPS, dan membantu mengimplementasikan keterampilan proses dalam proses pembelajaran.

3. Sekolah, agar memdukung dan melengkapi fasilitas pembelajaran yang mendukung proses pembelajaran khususnya implementasi pada aspek keterampilan proses.

Pengembangan proses model panduan pembelajaran tergantung pada kemauan, kemampuan pelaksana, serta kondisi pada tingkat satuan pendidikan.

\section{DAFTAR RUJUKAN}

Arikunto, Suharsimi. 2006. Prosedur Penelitian. Jakarta: Rineka Cipta 2009. Prosedur Penelitian. Jakarta: Rineka Cipta

Asih, Triana. 2012. Pengembangan Keterampilan Proses Sains Siswa Menggunakan Metode Inkuiri Terbimbing Berbasis Portofolio Siswa Kelas $\mathrm{X}_{4}$ SMA Negeri 1 Purbolinggo Semester Ganjil 
Tahun Pelajaran 2011/2012. Bioedukasi Jurnal Pendidikan Biologi FKIP UM Metro. Volume 3 Nomor 1 Mei 2012. Metro: UM Metro.

Borg, W.R. \& Gall, M.D (1989). Educational Research, Longman, New York London.

Cholvistaria, Mia. Penerapan Pembelajaran Berbasis Lingkungan dalam upaya Meningkatkan Keterampilan Proses Sains Siswa SMA Metro. Bioedukasi Jurnal Pendidikan Biologi FKIP UM Metro. Volume 3 Nomor 1 Mei 2012. Metro: UM Metro.

Haryono. 2006. Model Pembelajaran Berbasis Peningkatan Keterampilan Proses Sains. Jurnal Pendidikan Dasar. Volume 7 Nomor 1, 2006. Semarang: UNNES.

Jehdoloh, Rohaning. dan Portjanatanti, Nathavit. 2012. Effects of Inquiry-Base Learning on Science Chievment, Science Process Skills and Attitude Towards Science Student in Multicultural Society. Thaksin University Library Journal. Volume 1, Juli 2012. Thaksin, Thailand. University Thaksin.

Joice, Bruce. and Marsha, Weil. 1996. Model of Teaching. Boston: Allyn and Bacon

Karwono. dan Mularsih, Heni. 2012. Belajar dan Pembelajaran. Jakarta: Rajawali Pers.

Rezba, Richard J. 2012. Science Process Skills. Virginia: Kendall/hunt Publishing Company.
Rustaman, Nuryani. 2005. Strategi Belajar Mengajar Biologi Malang: UM Press.

Subagyo, Y., Wiyanto, dan Marwoto, P. 2009. Pembelajaran dengan Pendekatan Keterampilan Proses Sains untuk Meningkatkan Penguasaan Konsep Suhu dan Pemuaian. Jurnal Pendidikan Fisika Indonesia. Volume 5 Nomor, Mei 2009. Semarang. UNNES.

Yuniastuti, Euis. 2013. Peningkatan Keterampilan Proses, Motivasi, dan Hasil Belajar Biologi dengan Strategi Pembelajaran Inkuiri Terbimbing pada Siswa Kelas VII SMP Kartika V-1 Balikpapan. Jurnal Penelitian Pendidikan. Volume 14 Nomor 1, April 2013. Samarinda. Pascasarjana Univ. Mulawarman. 